\title{
COMPUTER AIDED ADAPTIVE SYSTEM DESIGN WITH ENGINEERING SYSTEMATICS AND MANUFACTURING
}

\author{
Gurkan Irsel ${ }^{1}$ \\ 1 Department of Mechanical Engineering, Trakya University, Edirne 22100, Turkey \\ e-mail: gurkanirsel@trakya.edu.tr
}

Received: 2017.09 .18

Accepted: 2017.11.01

Published: 2017.12.05

\begin{abstract}
This research practically discusses and presents the stages of design process in product development. Design process was realized through CATIA. The product developed is an agricultural device called as "disc harrow". Therefore, agricultural details are presented together with machine design. A roller system is added to disc harrow in this study. Thus; the current system and the additional roller system are discussed with the principles of methodological construction and design objectives are defined. Both the current system and the additional roller system are designed in parallel with these objectives. Structural stress analysis is performed at different kinetic positions of the disc harrow connection of the roller system. System design is achieved by considering the feedback from such analyses and design objectives. The hereby design is obtained. The additional roller system is mounted and field survey is carried out. Contribution of the roller to disc harrow process, defined design objectives, ratio of the realization of design objectives and results of stress analyses are evaluated.
\end{abstract}

Keywords: CATIA, structural analysis, shape design, adaptive structure, product development, disc harrow

\section{INTRODUCTION}

Today's modern agriculture industry requires a wide variety of equipment and special machine systems. Several factors such as the addition of new equipment, wearing of current equipment and fuel consumption significantly increase the costs of land processing operations [3, 4]. For sustainable agriculture, it has become important to reduce the costs of agricultural operations, to preserve soil quality to minimize the use of energy and to reduce the processing time [5].

Although mechanization needs of modern agriculture vary depending on several factors such as costs, climatic factor and stressed soil, there are some permanent mechanisms that are widely used. Disc harrow is one of these. Disc harrow is an efficient method for willow primary tillage in terms of power requirement [17]. A modular roller adaptation is aimed in order to al- low this traditional agricultural operation equipment to perform in a more efficient manner. Utilization of combined and modular systems is an effect solution for sustainable agriculture. Functional and modular product development would be a reasonable attempt to resolve the needs. Computer systems enables this process to become fast and economic.

Disc harrow, which was designed with CATIA in the product development stage, was studied with structural stress analyses. Weight and resistance relationship is significant in agricultural mechanization systems. An excessively heavy system would require a high bollard pull. Furthermore; it is difficult to carry a heavy machine on soil ground. Therefore; the methods used in the designs of computer-aided engineering based chassis, were analyzed. Javadi and Hajiahmad [8] aims of this research was to develop a new combined machine for sufficient clod breaking as well 
as surface uniformity in one pass and the shortest possible time. The machine was combination of a disk harrow and a Cambridge roller. The combined machine was field tested in a research station with loamy soil texture. Treatments of disk harrow once; disk harrow twice and combined machine applied after moldboard plowing. Using combined equipment and reducing number of passes has gained popularity due to its effect on time, efficiency and costs. Disk harrow is the most common equipment used for clod breaking compared to weed control or residue mixing after moldboard plow. Serrano et al. [22] soil-working operations in conventional farming systems involving the use of the tractor are some of the operations that incur the highest energy costs. Ozturk and Bastaban [19] combined machines such as spike harrow + disk harrow; disk harrow + packer roller and cultivator + spiked harrow had positive effect on soil loosening, bulk density and surface clod breaking. Rahman et al. [20] studied stress analysis on heavy duty truck chassis by finite element package ABAQUS. They suggested improving the fatigue life of components at critical points through design modifications by reducing stress. They suggested that, yield stress at critical points were decreased. Karaoglu and Kuralay [9] did stress analysis of heavy duty truck chassis with riveted joints by using a finite element package ANSYS version 5.3. They examined the effect of the side member thickness and connection plate thickness with length change. Tiwari and Joshi [25] mounted the gear models with CATIA. CAD data were transferred to ANSYS and stress analyses were performed. Krishan and Aggarwal [11] CAD modeling of the multi leaf spring structures also includes many complicated parts, which are difficult to make by any of other CAD modeling other than Finite Element software. CAD modeling of the complete Multi Leaf Spring structure is performed by using CATIAV5 R17 software. Nor et al. [18] determine the stress analysis of an actual low loader structure having I-beams design application of 35 ton trailer. They use CATIA V5R18 for modeling. Agrawal [2] in Static Analysis, we can determine highly stressed area of truck chassis. Kotari and Gopinath [13] modeled chassis through CATIA and performed ANSYS stress analyses. They turned a system with a load bearing capacity of 10.4 tones into a system with a load bearing capacity of 14 tons. Agrawal and Razik [1] used CATIA and ANSYS to perform an optimization study. Truck chassis was designed with CATIA.
ANSYS was used in analyses. Magdziak [16] performed his turbine wing with the assistance of CATIA optimization method. Irsel [7] Computer Aided Engineering Design Optimization process is studied experimentally with CATIA Product Engineering Optimizer module and optimization algorithms within limitations are used. Benefits of the optimization procedure are also evaluated. Optimization process has great importance in the design of machine parts and constructions. One of the primary duties of engineering is to offer a more resistant and a lighter structure and to minimize the stress in the system. Besides resistance and weight, there are too many design parameters to be evaluated and considering too many design parameters will bring along too many solutions. Thus, it will be wise to use an optimum design in the analysis to achieve the desired goal [10]. In this research, a compressed seed bed involving tinier particles in a single pass with disc harrow was integrated with a roller in order to obtain a smoother surface.

The basic purpose of this research is to offer the design of a roller system mechanism to be adapted to the current disc harrow and to produce and evaluate such design. With respect to that, the design was revealed out through the principles of methodological construction and dimensions were determined through mounting stress analyses. Structural stress analyses were performed with CATIA for VI different positions representing a cycle activity. The designed system was then produced. Field surveys were performed. The results were presented through tables and figures.

\section{MATERIAL AND METHOD}

\section{Description of the Current System}

The disc harrow discussed here is the offset type disc harrow with $46 \mathrm{~cm}$ disc diameter. Discs are placed in two rows. The row looks has a "V" form when looked from above (Figure 1). Concave surfaces of the discs are in opposite direction to each other in the first and second rows. Commonly, there is $17 \mathrm{~cm}$ to $24 \mathrm{~cm}$ distance between the discs. $46 \mathrm{~cm}, 51 \mathrm{~cm}$ or $56 \mathrm{~cm}$ are frequently used in agricultural processes in Turkey. The structure obtained after processing with discs with a diameter above $51 \mathrm{~cm}$ would be deeper and have fewer particles.

The disc harrow used in this research have 36 discs. Disc harrow requires $25-33 \mathrm{kWm} / 1 \mathrm{~m}$ trac- 
tor bollard pull depending on the type of soil and wetness [23]. Figure 1 presents light type (disc with $46 \mathrm{~cm}$ diameter and $17 \mathrm{~cm}$ disc distance) disc harrow. The two carrier wheels available in the middle part of the system contact the ground and pull the system up with the aid of a hydraulic cylinder and mechanism. Thus; the contact of discs with the ground is broken. This is a very useful and ergonomic method both during performance and on the way. Furthermore; the carrier system is related to the pull profile of the tractor with an upper bond. This bond is mostly connected to the pull profile by a spring. This upper bond is used in the contact of the main chassis of disc harrow with the ground and to preserve the horizontal position on the way.

When authentic offset disc harrow models produced by different manufacturers are examined, the most important difference that comes out is the constructive robustness and weight. Too much constructive weight cause discs to go much deeper into the ground. Disc harrows with 20-36 discs have weight varying from 1350 to $3500 \mathrm{~kg}$. When discs go into the ground deeper than desirable level; mounting beds contact the ground and wear out, oil seals are stressed, bearings are filled with tiny sand particles and there emerges the need for greater bollard pull. The need for greater bollard causes excessive fuel consumption, reduction of work capacity and speed and thus, leads to reduction of processing capacity. Therefore; minimum weight and weight that could be added to the system are significant for various agricultural mechanization systems. There are also disc harrows which possess a main chassis that can be filled with water.

\section{Design Objectives}

Considering the design factors with respect to the functionality of disc harrow; machine-ground constructive relationship, bollard pull requirement and cost per cycle are the most important

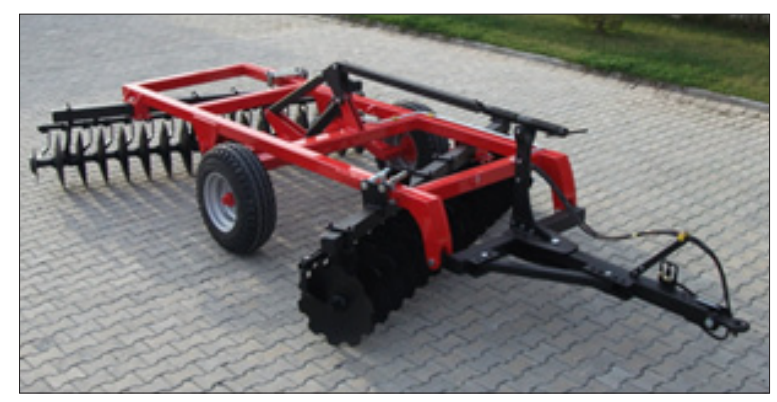

Fig. 1. A common offset type disc harrow factors. Methodological construction design objectives were defined in order to achieve a design that would have a positive effect on these important factors:

- For the functionality of the roller, the breadth of the roller to be added to the system will be $20 \mathrm{~cm}$ wider that the current disc harrow breadth. Consequently; the breadth of roller will be $3.5 \mathrm{~m}$.

- The roller to be mounted on the main chassis of disc harrow will be of modular type and it will be suitable for use with different agricultural machines.

- Disc harrow-roller carrier for modular systems will be able to carry different equipment, as well. Therefore; carrier connection will be suitable for a standard profile.

- It will be possible to deactivate roller by hydraulic cylinder when there is no need for its operation. This will be performed from the tractor and be ergonomic.

- Roller will be close to disc harrow's center of gravity on the way and will be located on the chassis.

- As the diameter of the roller gets larger, rolling resistance decreases but weight increases. Taking disc harrow's disc diameter into consideration, it would be suitable for the roller to have a diameter of $500 \mathrm{~mm}$.

- There will not be a shaft passing through the center of roller in order to prevent soil stick on the roller.

- Roller-ground surface contact sheets will not be in a plain form. A conic profile with depth is required for compression.

- Roller contact sheets must have helical order. This is significant for continuous contact of the roller with the ground. Otherwise, roller cannot apply an equal pressure force on the surface.

- Roller will only be bedded from its two sides in order to prevent that there is no breadth left non-contact throughout the processing breadth.

- The roller attached to the back side of the current system will change the gravity center of the system. Thus; the current system balancing connection will be adjusted by a hydraulic cylinder. This process is not related with roller connection system design.

- The roller will not be of additional weight to the disc harrow. When the roller is in contact with the ground, it will be able to carry its own weight without submerging. Therefore; the 
sheets to contact with the ground in a helical way will have $10 \mathrm{~mm}$ wall thickness.

- For this system it would be appropriate to take security coefficient as 2 in the work area and as 4 on the way.

- The weight of roller will vary from 60 to 70 $\mathrm{kg}$ per meter.

- Roller connection fork will have maximum $200 \mathrm{~kg}$ weight.

- It would be sufficient to use one hydraulic cylinder for the roller system. The hydraulic cylinder selected here possesses $780 \mathrm{~mm}$ closed $1260 \mathrm{~mm}$ open position and $480 \mathrm{~mm}$ stroke. Design will be shaped in parallel with the dimensions of hydraulic cylinder.

- Maximum stress will necessarily be on mounting pins. This is important for eliminating the any system damage with minimum cost.

\section{Adaptive Design with CATIA}

CATIA's Part Design, Assembly Design, Generative Structural Analysis and Drafting modules were used in this research. Parts were modeled and mounted, stress analyses were mostly performed during mounting. Necessary details for plasma shear and production were transferred to 2D environment in drafting module.

\section{Modeling of the Current Disc Harrow Chasis}

Main chassis of a common disc harrow has a simple and plain structure, indeed. It consists of a rectangular body made of standard rectangular profiles and of connection elements [8]. The main chassis presented in Figure 2 for roller adaptation design is made of $150 \mathrm{~mm} \times 100 \mathrm{~mm} \times 8 \mathrm{~mm}$ standard profiles. Wheel connection plates were also created for analysis. As the whole system is going to be studied through stress analysis, this chassis design is sufficient to protect against the negative impact on computer capacity.

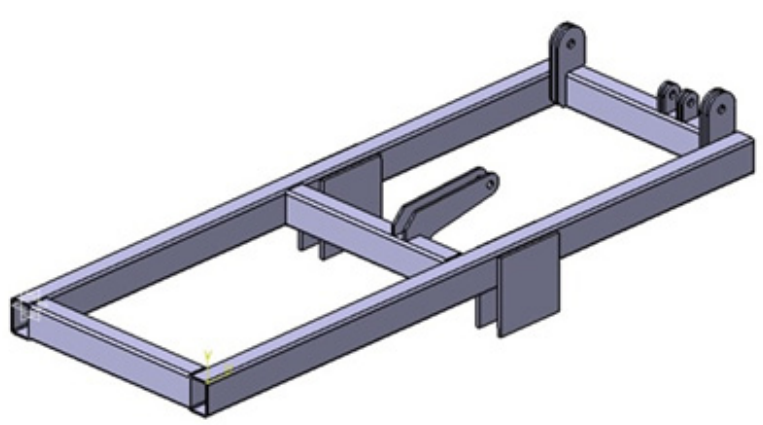

Fig. 2. Main chassis of a common disc harrow

\section{Modeling of the Roller}

Plate arrangement of a helical positioned roller with $50 \mathrm{~cm}$ outer diameter is presented in Figure 3 . The conic shaped structure to compress the ground is presented in Figure 4.

Roller contacts the ground at each moment of rolling. Material of the designed roller is $\mathrm{St}$ 37 and its weight is $235 \mathrm{~kg}$. Roller design is presented in Figure 5. Shaft is designed for bedding to the flanges on two exterior sides of the roller. These shafts are bedded to the roller. Shaft diameter is $50 \mathrm{~mm}$.

Two pieces of SKF brand shaft bed unit are preferred for roller bedding. This unit consists of a bed, bearing and seals. Each unit is mounted using 4 screws and becomes ready for use. Bed lifetime for SKF bearings is calculated on the online calculation module [24].

\section{Carrier Fork Design}

Carrier roller fork was created in parallel with the principles of methodological construction. This fork can be used for the mounting of 100 $\mathrm{mm}$ square sectioned profiles. Form fastening and profile were wrapped from the bottom using jaws. While the $100 \mathrm{~mm}$ square profile was inside the jaws, mounting was performed from the upper part using one plate and two screws for each. Left, right and up motion of this connection profile was restricted. The box profile positioned in

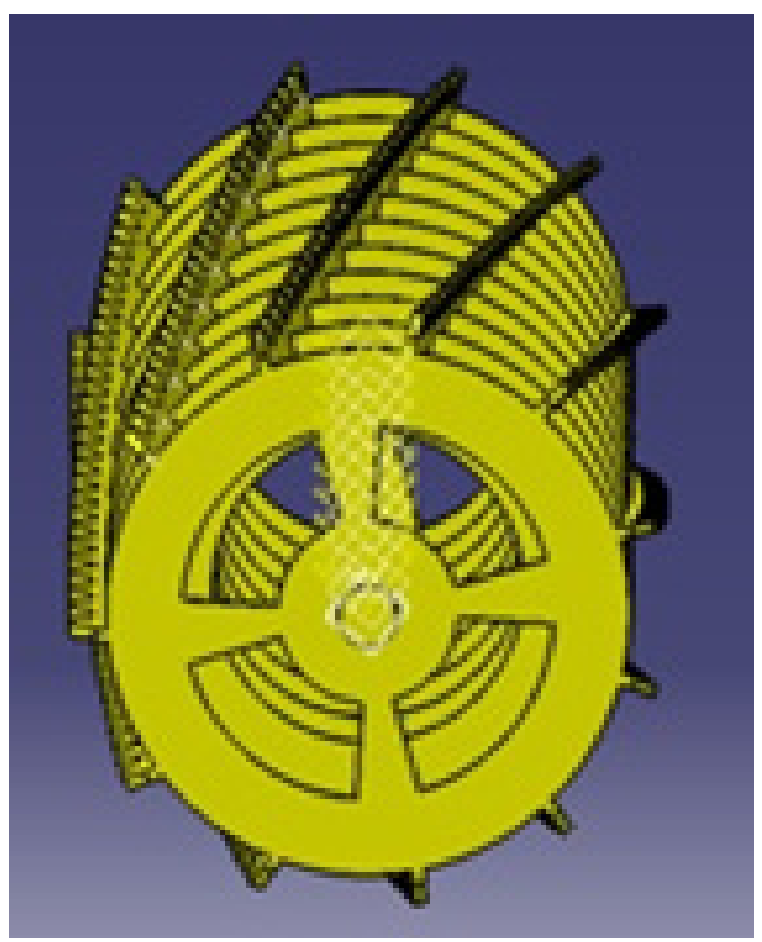

Fig. 3 Roller plate arrangement. 


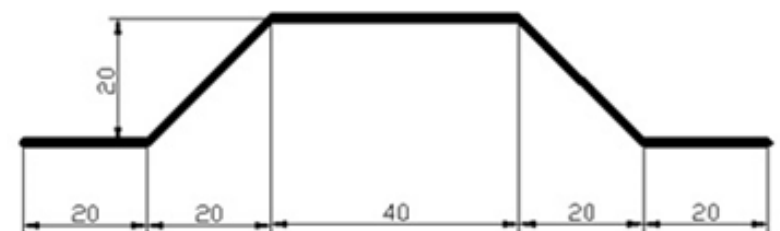

Fig. 4 Plate - rich contact conic profile.

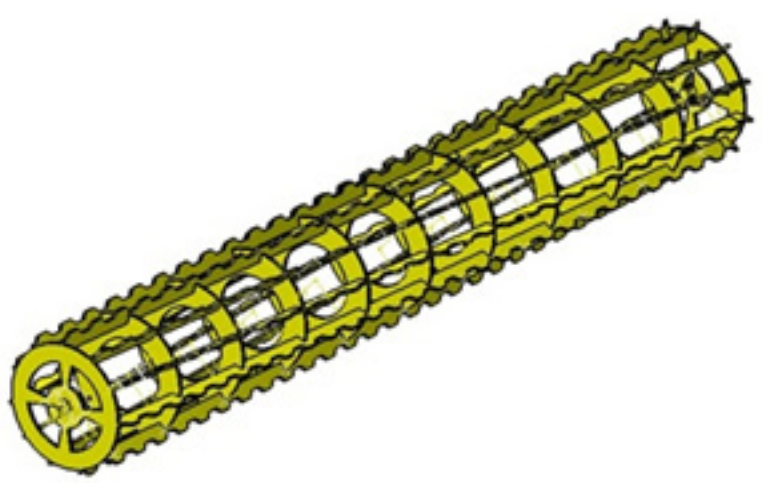

Fig. 5. Roller design solid model

the middle of the two forks made the chassis of the fork carrier. Hydraulic system connection was made on this profile. The two holes seen on the carrier fork in Figure 6 were made for connection to the main chassis of the disc harrow.

With pins, the carrier fork was mounted between twosome plates welded on disc harrow through two upper holes. Pin-connected mounting was performed in such a way that one arm of the fork would be the other arm between the other two plates. The distance between two forks was $781 \mathrm{~mm}$ at chassis-carrier fork connection. The fork was at bottom position with $115.2^{\circ}$ angle

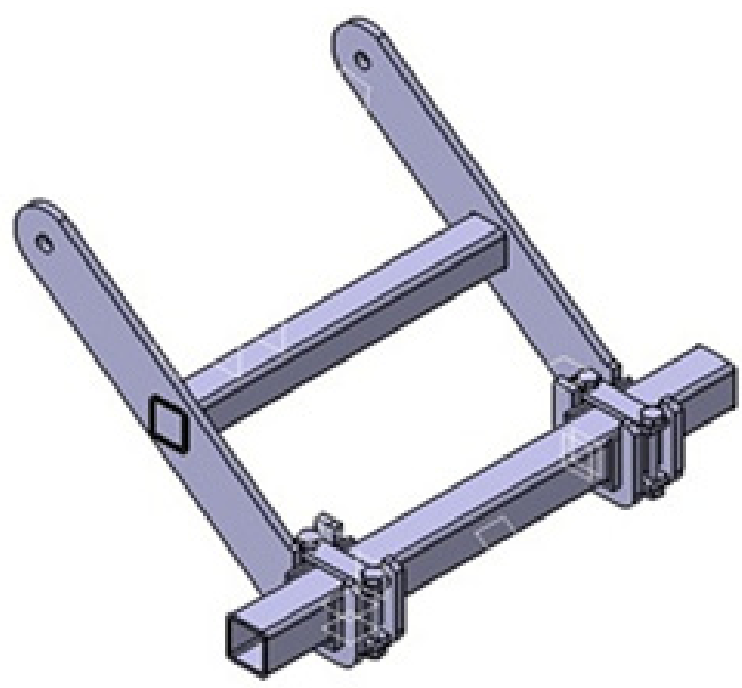

Fig. 6. Carrier fork system
(Figure 7). When the fork was in this position, the roller was positioned according to the chassis of disc harrow. This distance would be suitable to make sure that discs would not spill soil on the roller. SKF 205 bearing units were mounted on the shafts welded on roller side flanges .

At this position of roller, two side plates were formed. Two $20 \mathrm{~mm}$ holes were drilled on this plate. These holes are for system mounting hanger and for the attachment of any additional system on the roller (Figure 8).

\section{Carrier Fork - Hydraulic Cylinder Mechanism Design}

In Figure 9, there is a section belonging to the roller motion mechanism. This section is a general view at $345 \mathrm{~mm}$ stroke of the hydraulic cylinder. Shorter arms in $270 \mathrm{~mm}$ length determine the roller's motion depending on the hydraulic cylinder stroke.

The detail regarding the roller motion mechanism design was presented in Figure 10 with the kinematic analysis of the mounting design. Roller's motion was studied for 6 positions for $480 \mathrm{~mm}$ hydraulic cylinder stroke.

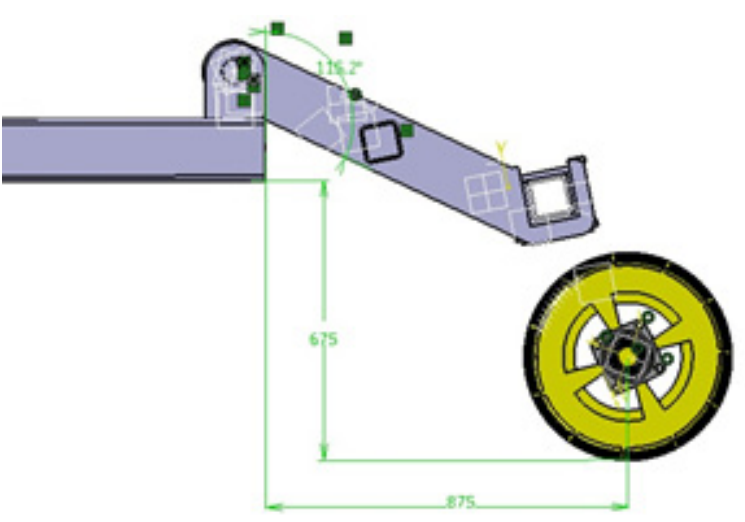

Fig. 7. Roller- Fork carrier-Disc harrow positioning

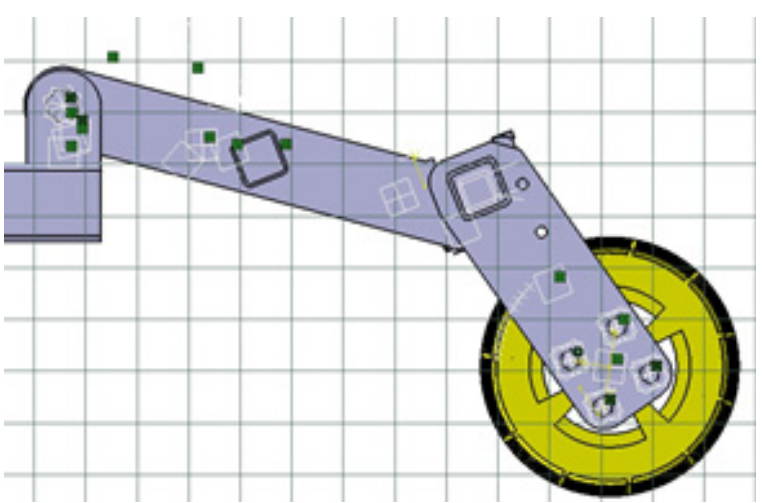

Fig. 8. Roller bed connection plates design 


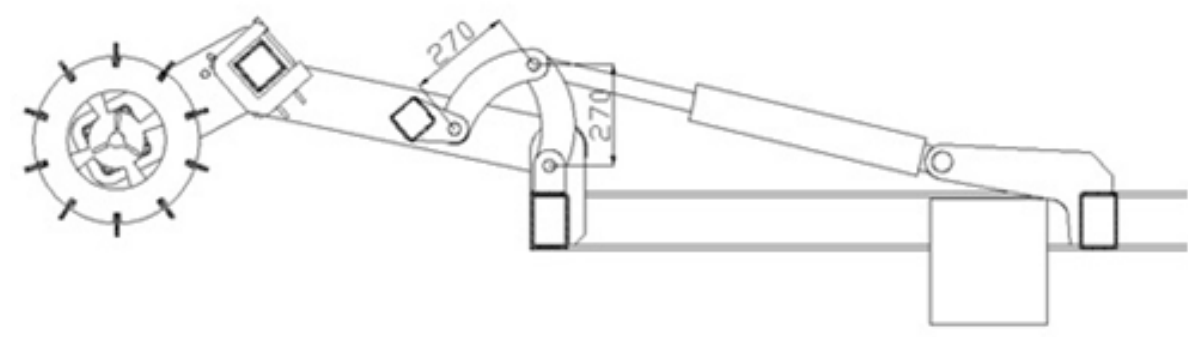

Fig. 9. Roller mechanism lateral section

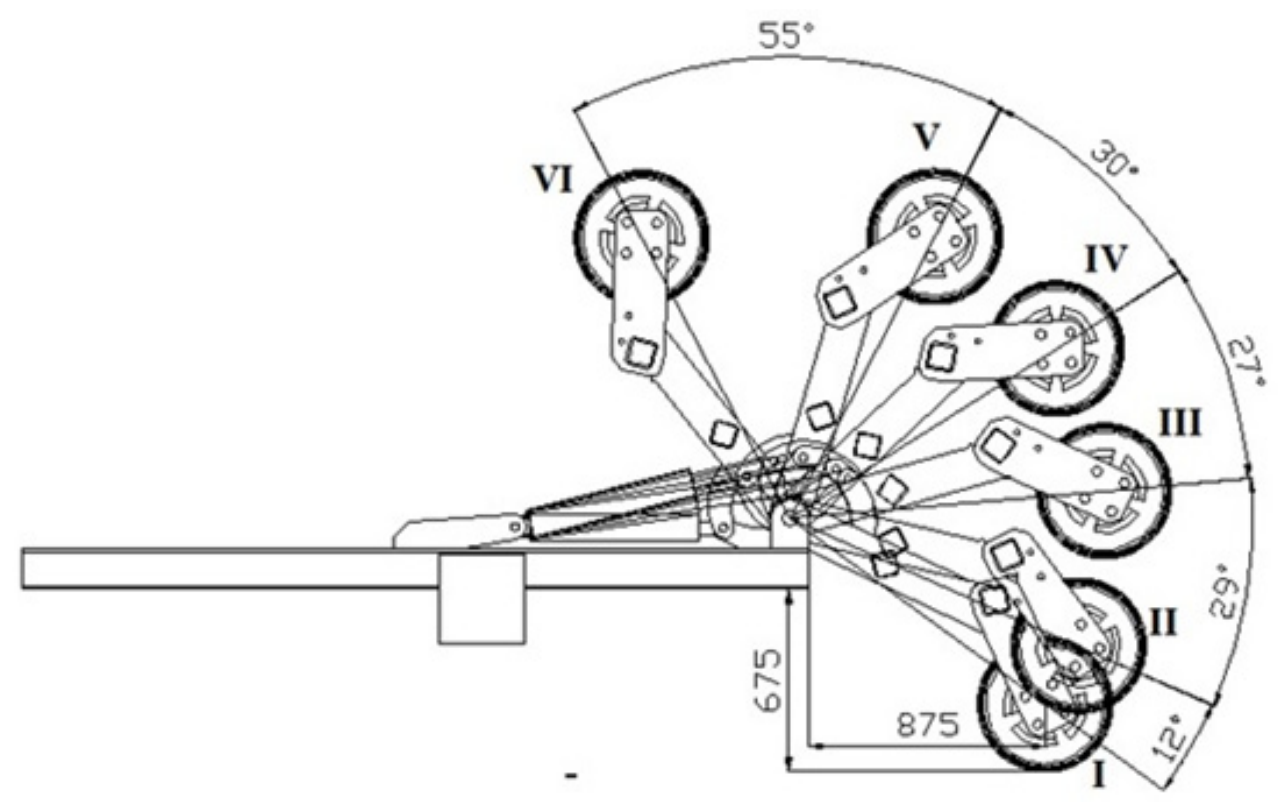

Fig. 10. Roller position depending on the stroke change of the hydraulic cylinder

Roller position was: I for $480 \mathrm{~mm}$ maximum stroke of the hydraulic cylinder and it was: VI for $2 \mathrm{~mm}$ stroke of the hydraulic cylinder. 478 $\mathrm{mm}$ stroke was used in total to have the $2 \mathrm{~mm}$ hydraulic cylinder to keep the system at tense level. In this design, the area between position I and positions I-II is the processing area of the roller. In this area, maximum vertical motion aimed and enabled for the minimum progress of the hydraulic cylinder. For $1 \mathrm{~mm}$ progress of the hydraulic cylinder, the roller performs 5.30 $\mathrm{mm}$ vertical motion in average. Between positions V-VI, the roller performs $7.66 \mathrm{~mm}$ horizontal motion in average for $1 \mathrm{~mm}$ progress of the hydraulic cylinder.

Once connection points and arm lengths were determined, hydraulic cylinder roller motion mechanism solid model was created (Figure 11).

\section{Structural Stress Analysis of Adaptive System}

The ground-based vertical force on the arm system roller F1 and horizontal force was F3 whereas the force on the hydraulic cylinder was F2. F2 force was created with the directing of the $270 \mathrm{~mm}$-long arms. In structural stress analysis,

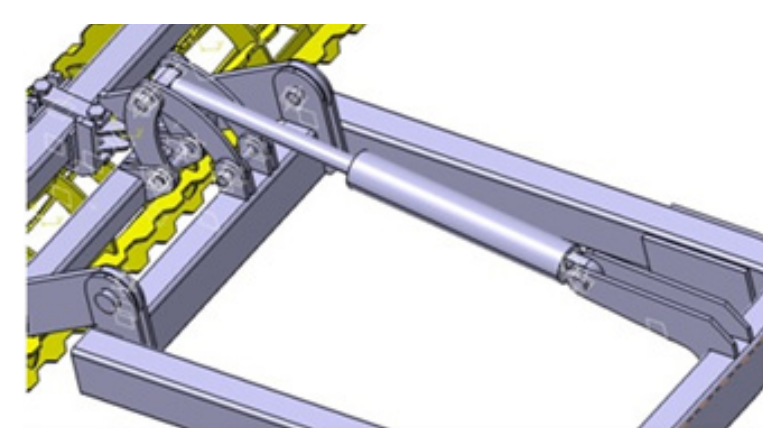

Fig. 11. Hydraulic cylinder - roller motion mechanism model 
F1 and F3 forces were defined the compound force as a single force (Figure 12).

Total weight of roller and fork carrier was 433 kg. $4.5 \mathrm{kN}$ distributed load was applied on roller on the way. As the weight of the chassis could also pose a pressure on roller during contact with the ground a $8 \mathrm{kN}$ force was applied. Under the influence of these forces, the system was studied with structural stress analysis during mounting.

The connection between the mounted parts was defined with general analysis connection icon. The analysis had 37 connections (Figure 13).

The system consists of 26 parts. Thus; the analysis involves 26 different mesh definitions. General analysis connection definitions are of fastened mesh nature. It is important to create suitable mesh structure in CAD programs using finite elements methods for the performance of structural stress analysis. Linear element was used. Global error rate was 34\% for the selected mesh size (Figure 14).

As in Position I, stress analysis was performed with $8000 \mathrm{~N}$ load, max $111 \mathrm{MPa}$ Von Misses stress result was achieved maximum stress was observed on mounting pin (Figure 15). Maximum collapse value was detected to be 17.4 $\mathrm{mm}$ in Position I (Figure 16). Maximum stress value was 53.9 MPa (Figure 17) at Position IV. Maximum collapse value was $8.37 \mathrm{~mm}$ at Position IV (Figure 18). Stress value at Positions II, III and IV was around $50 \mathrm{MPa}$. Maximum stress value at Position VI was 43.9 MPa (Figure 19). Maximum collapse value was $2.88 \mathrm{~mm}$ at Position VI (Figure 20).

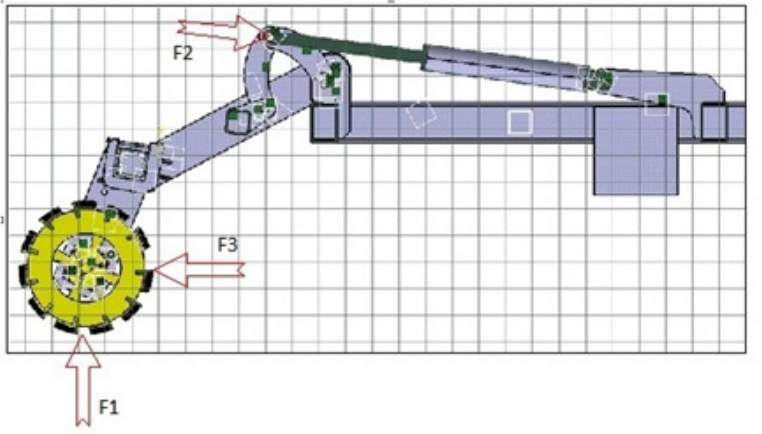

Fig. 12. Roller system section and force effect

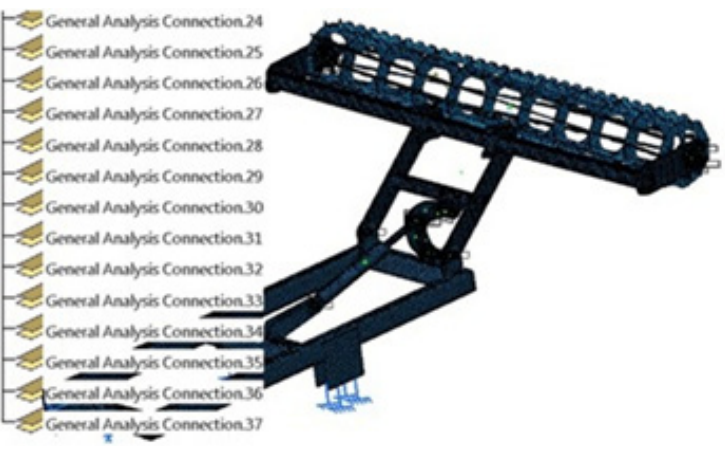

Fig. 13. General analysis connection and mesh design

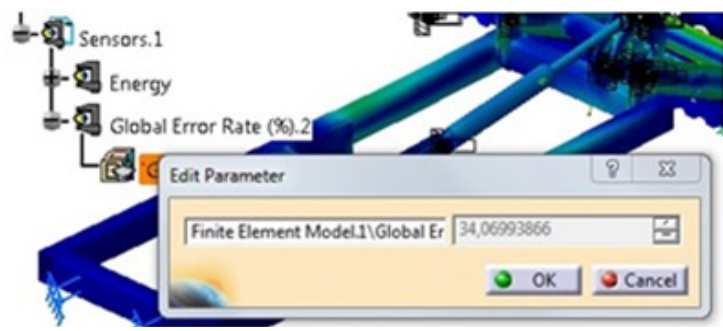

Fig. 14. Global mesh error rate

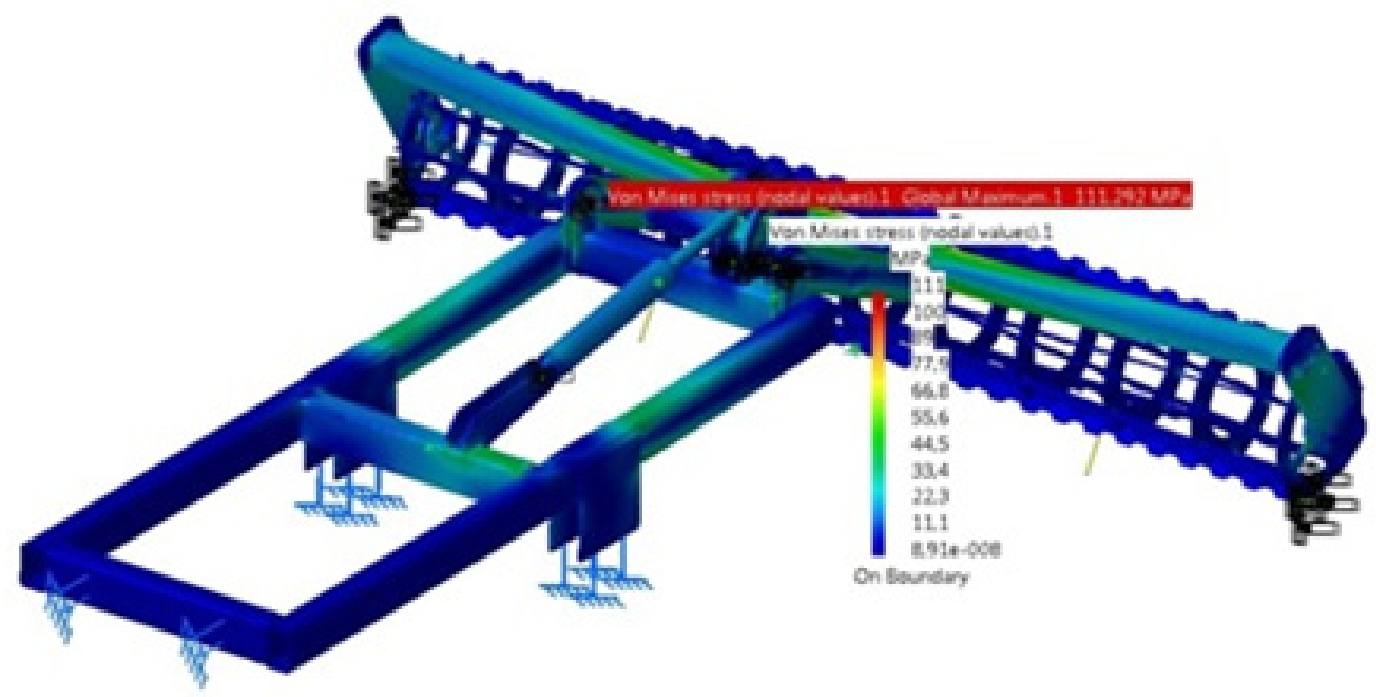

Fig. 15. Stress analysis at Position I 


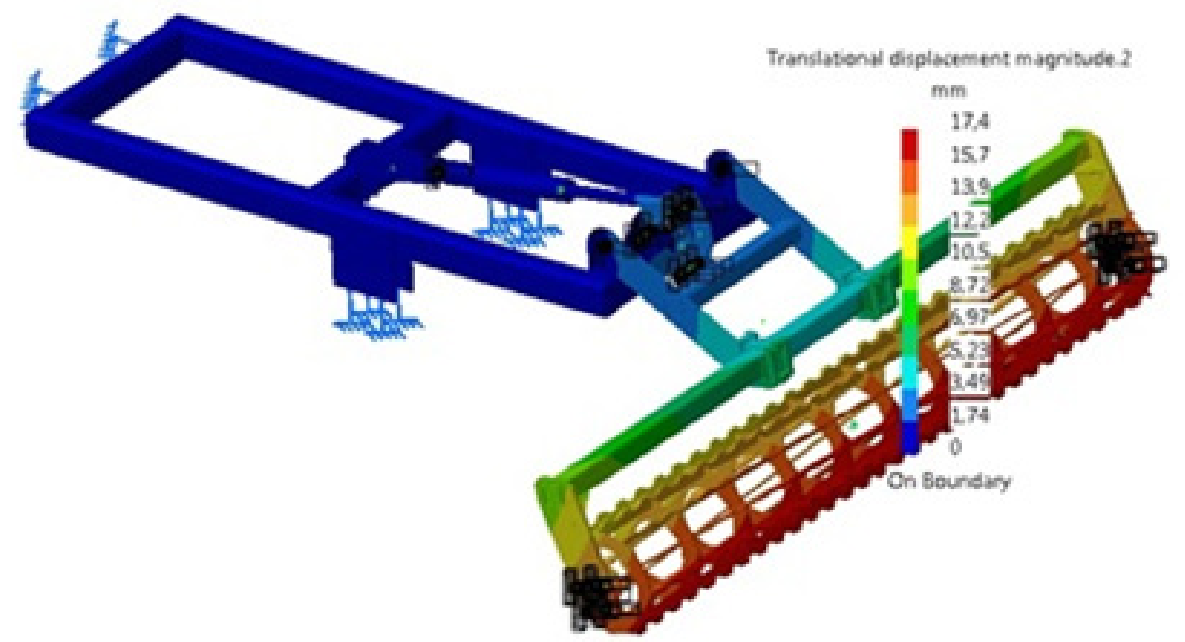

Fig. 16. Collapse distribution at Position I

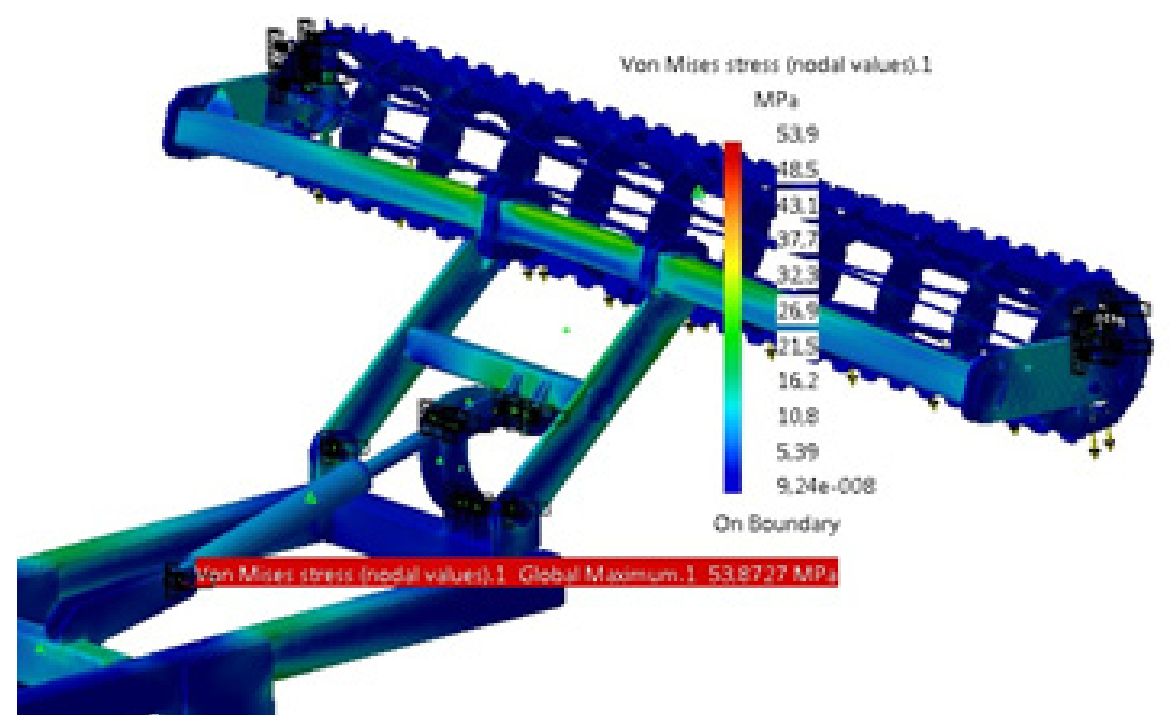

Fig. 17. Stress analysis at Position IV

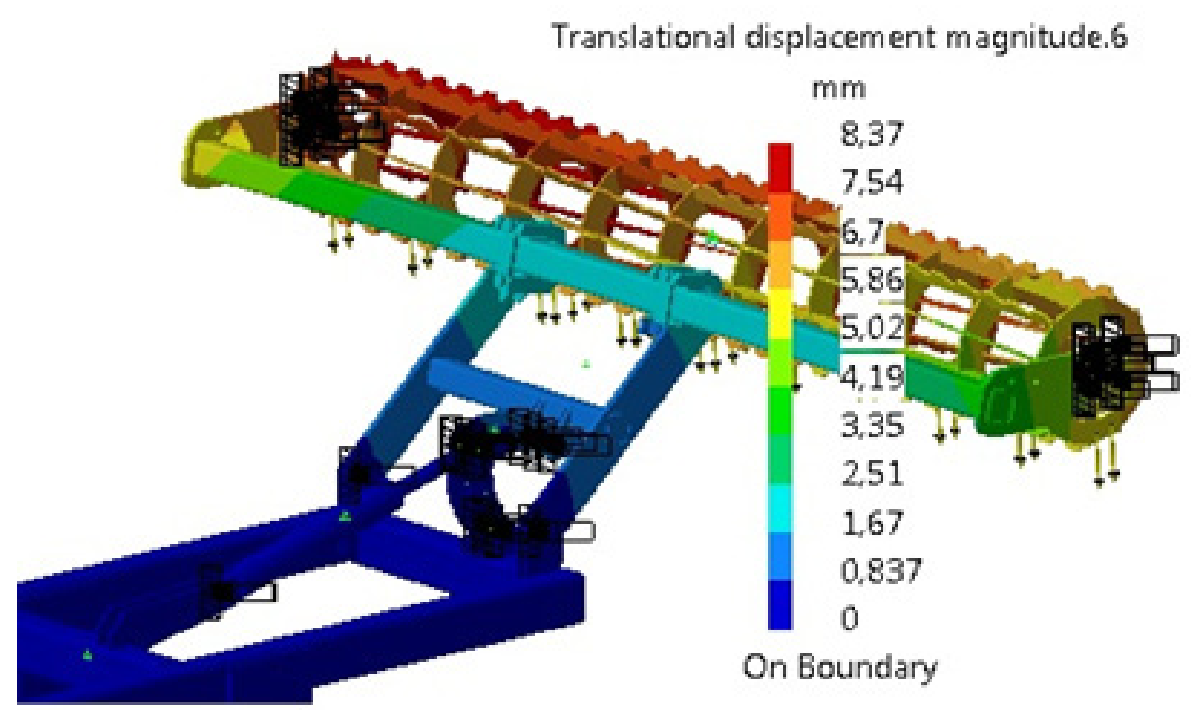

Fig. 18. Collapse distribution at Position IV 


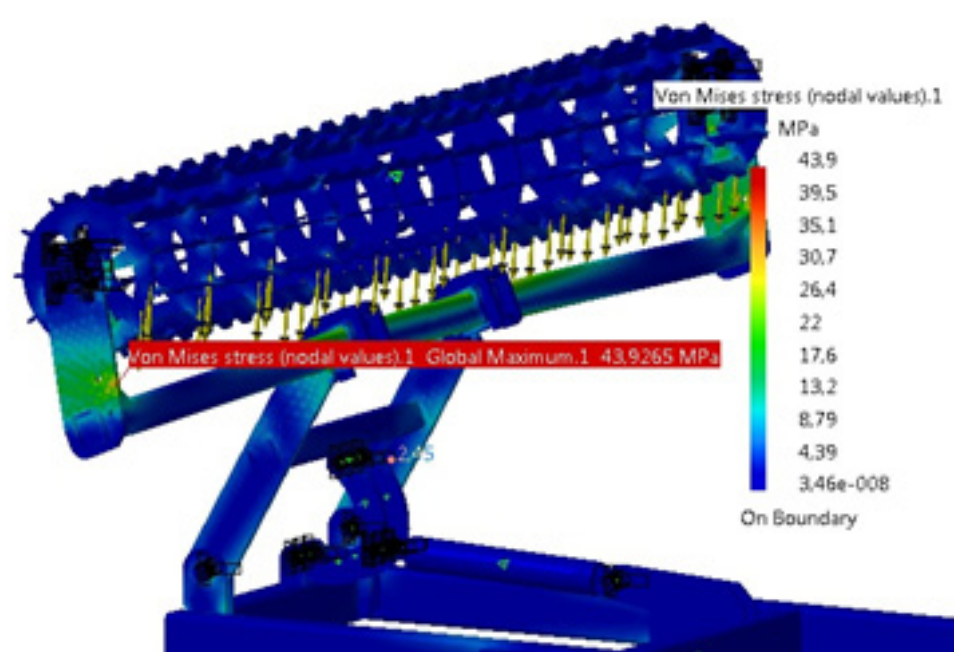

Fig. 19. Stress analysis at Position VI

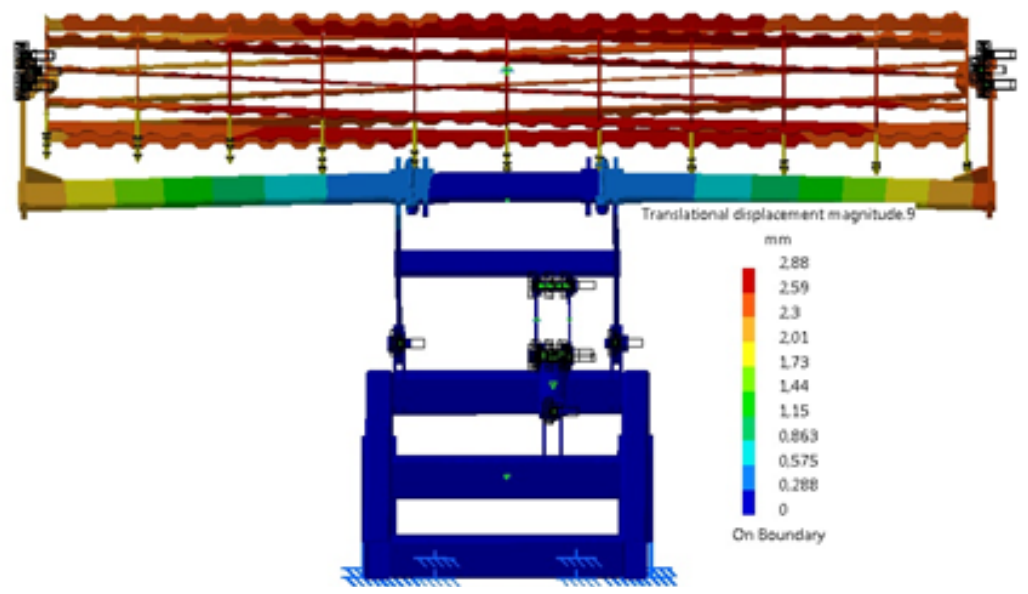

Fig. 20. Collapse distribution at Position VI

\section{RESULTS}

Roller adaptation system design was made through systematic and planned (methodological) evaluation of several factors such as weight, material, motion, mounting, transportation, energy, ergonomics, security, drive method, production method etc.

The system was studied at 6 different positions depending on the hydraulic cylinder stroke (seen in Figure 8). Kinematic motion of the roller desirable at $\mathrm{X}$ (horizontal) and $\mathrm{Y}$ (vertical) angles depending on the stroke of hydraulic cylinder was achieved through the sizing of parts. At Position I and II, the roller performs around $5.30 \mathrm{~mm}$ vertical motion for $1 \mathrm{~mm}$ progress of this hydraulic cylinder between these two positions. For $1 \mathrm{~mm}$ progress of hydraulic cylinder between Position $\mathrm{V}$ and VI, the roller performs around $7.66 \mathrm{~mm}$ vertical motion. Table 1 presents the amount of motions at $\mathrm{X}$ and $\mathrm{Y}$ angles depending on hydraulic cylinder stroke.

The design was analyzed with structural stress analysis. The structural analysis performed in this research consists of 26 parts. Linear element was selected for mounting system elements in CATIA Generative Structural stress analysis. Global mesh error rate for the selected mesh size was achieved as $34 \%$. Analysis report belonging to the finite elements model mesh structure created with CATIA is presented in Table 2.

Mesh propagation is suitable for this system. Table 3 presents the maximum stress and maximum collapse values achieved at structural stress analyses performed for 6 different positions representing the whole structural resistance $(8 \mathrm{kN}$ distributed load at Position I, $4.5 \mathrm{kN}$ distributed load at Positions II and IV).

Design criteria was obtained by CATIA design. 
Table 1. The amount of motions at $\mathrm{X}$ and $\mathrm{Y}$ angles depending on hydraulic cylinder stroke.

\begin{tabular}{|c|c|c|c|c|c|}
\hline $\begin{array}{c}\text { H. cylinder stroke } \\
(\mathrm{mm})\end{array}$ & $\begin{array}{c}\text { Positions (figure } \\
13)\end{array}$ & $\begin{array}{c}\text { H. cylinder ctroke } \\
\text { difference }\end{array}$ & $\begin{array}{c}\text { Angle difference } \\
\text { (degree) }\end{array}$ & $\begin{array}{c}\text { Stroke at Y angle } \\
(\mathrm{mm})\end{array}$ & $\begin{array}{c}\text { Stroke at X angle } \\
(\mathrm{mm})\end{array}$ \\
\hline $480-440$ & I-II & 40 & 12 & +212.30 & +124.42 \\
\hline $440-330$ & II-III & 110 & 29 & +577.16 & +97.09 \\
\hline $330-220$ & III-IV & 110 & 27 & +528.46 & -179.36 \\
\hline $220-110$ & IV-V & 110 & 30 & +417.96 & -450.63 \\
\hline $110-2$ & V-VI & 110 & 55 & -3.87 & -1090.90 \\
\hline
\end{tabular}

Table 2. analysis report for 34\% global mesh error rate

\begin{tabular}{|c|c|c|c|c|}
\hline \multicolumn{2}{|c|}{ Mesh } & Element type & \multicolumn{2}{c|}{ Element quality (\% Good) } \\
\hline Nodes & Elements & \multirow{2}{*}{ Linear } & Stretch & Aspect ratio \\
\cline { 1 - 4 } 113945 & 407205 & & 99.51 & 76.62 \\
\hline
\end{tabular}

Table 3. Stress analyses and collapse values for roller carrier system at 6 different positions

\begin{tabular}{|c|c|c|c|}
\hline Carrier position & Max von mises stress (MPa) & $\begin{array}{c}\text { Max. collapse value } \\
(\mathrm{mm})\end{array}$ & Security coefficient \\
\hline I & 111 & 17.4 & 2.12 \\
\hline II & 59.8 & 6.21 & 3.93 \\
\hline III & 51.2 & 8.12 & 4.58 \\
\hline IV & 53.9 & 8.37 & 4.35 \\
\hline V & 44.8 & 6.09 & 5.24 \\
\hline VI & 43.9 & 2.88 & 5.35 \\
\hline
\end{tabular}

The $500 \mathrm{~mm}$-diameter, 3.5 meter wide roller system is bedded with 2 flange bed units. Roller beds have a lifetime of 2.49 x 109 cycle processing capacity. There is a shaft at the center of roller going across the length of the roller.

Different equipment can be attached on the designed fork carrier using a $100 \mathrm{~mm}$ box profile. The roller system differs from disc harrow with the demounting of 3 pins only. The roller system is activated by the operator by hydraulic valve. Roller pressure force is easily adjusted by changing the position of the roller. The roller's weight is $235 \mathrm{~kg}$ and the carrier fork's weight is $198 \mathrm{~kg}$. The roller's weight is $67.14 \mathrm{~kg}$ per meter. Maximum stress is on mounting pins.

Roller surface contact plates are in helical organization and in conic form applying a compression on the ground. We achieved a modular roller system that could be used for several applications. The carrier system is also suitable for connection with different equipment.

The system is 2 times safer in operation state and minimum 4 times safer on the way. The design was built through CATIA. 2D images of 3D design were achieved through CATIA Drafting module. Sheet parts forming the design were cut by plasma shear device. The cut parts were connected with Under Gas Arc Welding. The roller was achieved in this way. SKF bed units were mounted on side plates welded on $100 \mathrm{~mm} \times 8$ $\mathrm{mm}$ square box hanger profiles (Figure 21). Short arms and fork carrier are presented in Figure 22. Figure 23 presents the hydraulic cylinder and roller system mounted on disc harrow. The system is at Position I. The roller is on way position no. VI in Figure 24. The desirable design was achieved in this way. As desired for modular roller system, a different disc harrow was used in a modular way (Figure 25).

The final design was achieved by one worker within a time period as short as 20 hours. Adaptive roller system was mounted and field survey was performed.

The benefit desired regarding the additional roller design was achieved by the system. The design created in parallel with design objectives, is ergonomic. Design objectives are reasonable and well-defined. Analysis results of the design are accurate and applicable. The system revealed out expected results in analysis. 


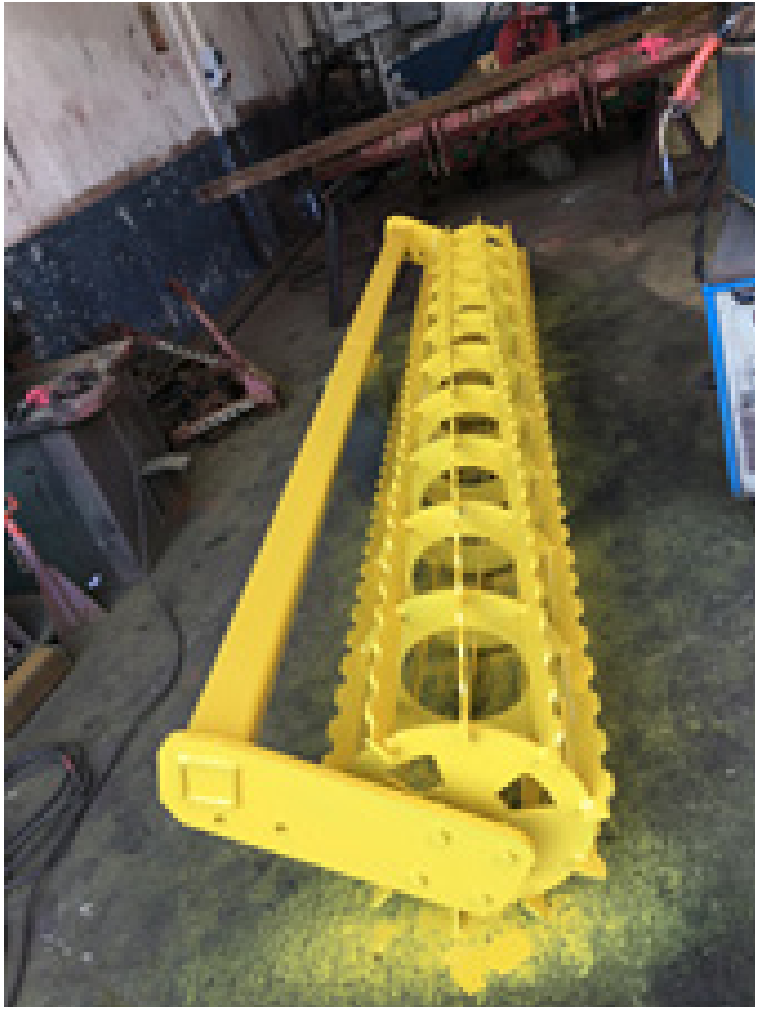

Fig. 21. Roller manufacturing

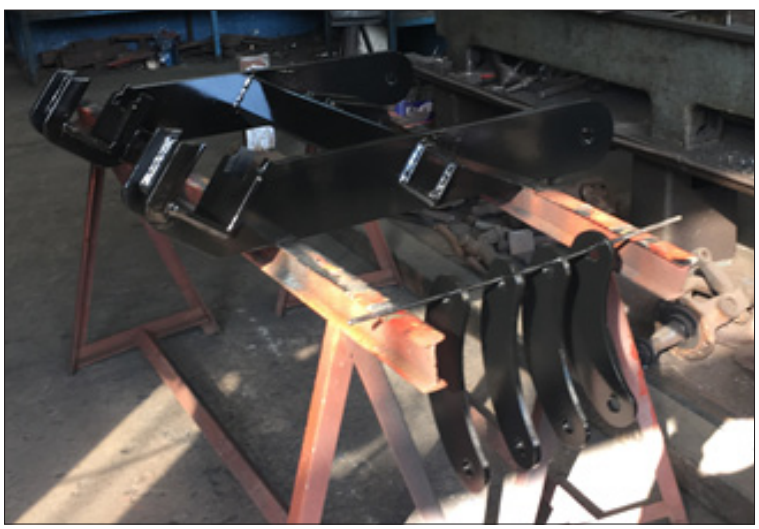

Fig. 22. Short arms and fork carrier were produce.

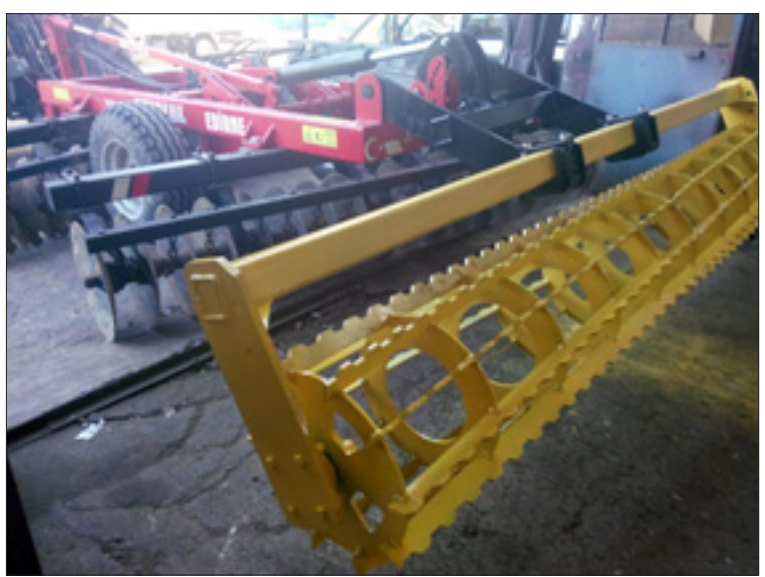

Fig. 23. Roller at Position I.

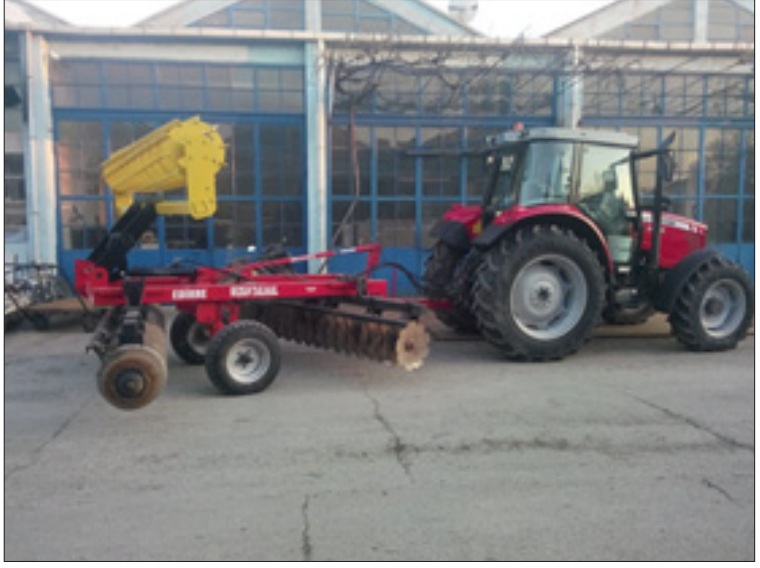

Fig. 24. Mounting of disc harrow with roller system way position.

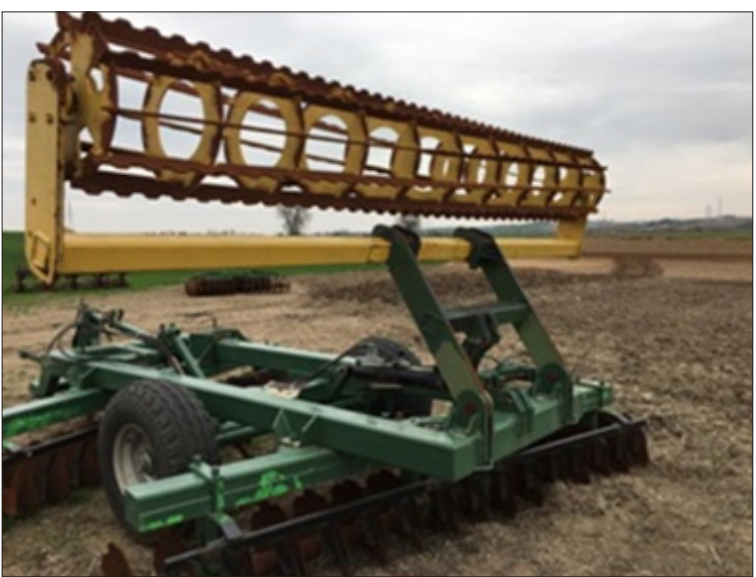

Fig. 25. Heavy type disc harrow and roller - way position

The system was used in 5000-decare land study. No damage occurred in the carrier system or in roller system.

\section{DISCUSSION}

Methodological solution used in this research enabled complete, simple, fast and successful access to the final objective. Furthermore; modularity brought along benefits such as identification of damaged area with design and elimination of any potential missing details. Not using methodological solution in construction is the biggest mistake and the main reason for failure and the chances of solution that go unnoticed [14].

Modern industry has focused on computeraided analyses for achieving shorter product development time, fast marketing process, reliable and durable product design, production and optimization (Singh, 2014). With the emergence of 
faster computers and powerful FEA software, design engineers can now create larger, refined and complex models and thus, offer cost-efficient, proper and informative solutions to the problems of customers. Component analysis has been replaced by system analysis, i.e., structural analysis. With structural analysis, the effects of stress, shape change and location change are successfully measured under changing load conditions.

As stated by Zahariea [27], global mesh error rate will be lower than $40 \%$. In this research, stress analysis was performed with $34 \%$ global mesh error rate. Global error rate of the study is $34 \%$.

CATIA is a software that is commonly used in many important constructions for the reduction of stress for reorganization of damages systems. It plays a significant role in optimization studies. In research titled "Failure Investigation of the Disc Harrow Profiles and Redesigning by CATIA Analysis "conducted by Irsel et al. [6] maximum stress of $251 \mathrm{MPa}$, which was causing deformation, was reduced to $124 \mathrm{MPa}$. This was achieved by attaching an additional structure of only 140 $\mathrm{kg}$ weight to a system around $2000 \mathrm{~kg}$ weight Agrawal [2] in Static Analysis, we can determine highly stressed area of truck chassis due to applied load, and analytical shear stress is $13.33 \%$ less than FEA values.

Even in prototype studies, it is important to perform structural analyses of the system. Structural analyses give significant information about the future of the construction. Utilization of a construction without these calculations could cause loss of life and property.

In structural stress analyses, it is necessary to use an operation center particularly in cases where the number of parts is large and their size is big, just like in the research here.

Kocer performed a design and optimization study to ensure that stress accumulation would happen on the part that could accept the damage. Kocer (2007) assessed the weight and resistance ratio and created a design that would reduce the weight of relevant part in the main gear without compromising on its resistance. In this research, the area that had the potential to get damaged was identified with the design and the current mechanism was improved taking the weight/resistance criteria into consideration [12].

Karaoğlu [9] studied the stress analysis of truck chassis with riveted joints. It was concluded that if it is not possible to change the side member thickness using local plates, because of increase in weight of chassis then choosing an optimum connection plate length seems to be best practical solution for decreasing the stress values. As done by Karaoğlu, in this optimization study as well, optimal part size was determined depending on structural stress values.

Javadi and Hajiahmad [8] assessed roller adaptation in terms of agriculture. On the other hand; the roller they used was Cambridge type. It is suitable for dry soil type. Disc harrow and Cambridge roller combination is not used in agricultural operations in Turkey. The roller used in this research is $130 \mathrm{~kg} / \mathrm{m}$ lighter than Cambridge type roller and is in plate form. The plates contact the ground in a vertical position with intervals. Areas the plates do not contact are important for water absorption and for airing of soil.

This roller can operate on all wet grounds disc harrows can operate. A disc harrow is energy efficient for soil fragmentation during primary tillage [5].

Javadi and Hajiahmad [8] created the Cambridge type roller combination in screw-mounted form. Thus; roller contact depth cannot be changed. In the design achieved in this research, the roller is deactivated by hydraulic cylinder for an instant moment. This brings many benefits in for ergonomics and functionality.

In the design created by Javadi and Hajiahmad [8] there is a line in the middle part of the roller where the roller doesn't contact. In this research, bedding was made with two flanges outside the roller.

Utilization of roller brings benefits in agricultural operations. When roller is used, both the seed bed and root growth area are properly formed [15] It is also useful for the protection of the root against cold. The plant can benefit more from the soil and humidity available in compressed layer. It improves smooth surface fertility crated by rain or an irrigation process. Furthermore; roller-processed land enables more stabilized and efficient disinfection and harvesting operations.

Today, sustainability of agricultural operations can be achieved with the minimization of the number of agricultural operations with the utilization of combined systems Pietola [21]. In this respect, the roller system used in this research brought benefits in every aspect.

Roller also minimizes the wearing of tractor tires in the operations performed after dry land work. It enables a better working environment both for the operator and the tractor. 
This research achieved its purpose. It was observed in system production and field practices that, the defined design objectives were reasonable and appropriate.

\section{CONCLUSIONS}

1. In this research, an adaptation design was created in parallel with methodological construction principles through computer-aided engineering. A detail presentation was made for the computer-aided product development design process belonging to the modular roller system.

2. In order to obtain accurate results, it is important to study the system as a whole through structural stress analyses. The interaction between the parts contacting each other may not be clearly defined in component analysis.

3. Modification study period on systems possessing CAD data is quite short. In industries where time is highly important, such as agricultural operations, time is important for the organization of the mechanization system.

4. Though optimization studies require a high computer capacity, it is the most efficient way for achieving the best results in systems which are exposed to several parameters. Weight, maximum stress, global mesh error rate-oriented optimization studies are commonly performed by CATIA. In this research, an optimal design was successfully achieved in terms of security coefficients objectives and weight limits.

5. Part-related activities of mechanism are analyzed through the action of CATIA mounting design. Desirable roller activity is achieved depending on the activity of a hydraulic cylinder with a particular stroke.

6. Analysis of stress at different positions of mechanisms is significant. Structural stress analysis of a position may not be valid for all operation limits. In this research, varying security coefficients were achieved depending on the operation positions of the mechanism.

7. Systems possessing CAD data have shorter production time and lower costs. In this research, metal sheets were achieved through plasma shear method with CAD data.

8. Accuracy and authenticity of mounting is significant in structural stress analyses.

9. Field surveys revealed out that, roller was able to bring desirable agricultural benefits.
10. Computer-aided engineering is the most economic and fastest way to achieve the most efficient solution for all mechanisms.

11. Not using methodological solution in a design would be the biggest mistake and the basic reason for failure and loss of the chances for solution.

12. HP additional power was required for 3.5 meter wide roller operation. The benefit achieved in return for this amount was satisfying, indeed.

13. CATIA is commonly used in CAD data creation for other engineering programs. In several programs such as ANSYS etc., the design of the system to perform the analysis is created by CATIA before the analyses.

14. Numerical simulations based on FEM, verified with experiments, can be used as efficient and reliable tool in redesign of the complex construction such as bus construction that is used in our investigation [26].

15. Mesh structure forms the base for computeraided structural stress analyses which use the finite elements method. Therefore; the use of appropriate mesh size is closely related with the accuracy of the solution of the problem. Global mesh error rate in this research was $34 \%$ for the linear element.

16. Modular systems bring about many economic benefits for several mechanizations.

\section{Acknowledgements}

In this study, the bearings were supplied by SKF Türk San. ve Tic. Ltd. Şti.

\section{REFERENCES}

1. Agrawal M.S. and Razik M. A review on study of analysis of chassis. International Journal of Modern Engineering Research (IJMER), 3(2), 2013, 1135-1138.

2. Agrawal M.S. Finite element analysis of truck chassis frame, International Research Journal of Engineering and Technology (IRJET), 2(3), 2015, 1949-1956.

3. Alexandru P.H., Rudy M., Daniel V., Anton H., Ioan P. and Radu D. Modal analysis using fem of three active elements for an agricultural machine, Actual Tasks on Agricultural Engineering, Symposium 43,2013, 201-209.

4. Arvidsson J. Energy use efficiency in different tillage systems for winter wheat on a clay and silt 
loam in Sweden Department of Soil and Environment, Swedish University of Agricultural Sciences, 33, 2010, 250-256.

5. Arvidsson J., Keller T. and Gustafsson K. Specific draught for mouldboard plough, chisel plough and disc harrow at different water contents, Soil \& Tillage Research, 79, 2004, 221-231.

6. Irsel G., Altinbalik T. and Can Y. Failure investigation of the disc harrow profiles and redesigning by catia analysis, Applied Mechanics and Materials, 729, 2015, 181-186.

7. Irsel G. Stress analysis and design optimization with CATIA, Applied Computer Science, 12(1), 2016, 27-39.

8. Javadi A. and Hajiahmad A.Effect of a new combined implement for reducing secondary tillage operation, International Journal of Agriculture \& Biology, 8 (6), 2006, 724-727.

9. Karaoglu C. and Kuralay S. Stress analysis of a truck chassis with riveted joints, Finite Elements in Analysis and Design, 38, 2002, 1115-1130.

10. Karaçam F. and Timarci T. Stacking sequence optimization of composite beams with different layer thicknesses, Advances in Science and Technology Research Journal, 9(26), 2015, 7-11.

11. Krishan K. and Aggarwal L. A finite element approach for analysis of a multi leaf spring using CAE tools, Research Journal of Recent Sciences, 1(2), 2012, 92-96.

12. Kocer F. Multi-disciplinary design of an aircraft landing gear using concept design and optimization techniques, Proceedings of NAFEMS World Congress, 2007, 1-7.

13. Kotari S. and Gopinath V. Static and dynamic analysis on tarta chassis, International Journal of Modern Engineering Research (IJMER), 2(1), 2012, 86-94.

14. Kutay G. Construction systematics, http://www. guven-kutay.ch/konstruksiyon/30_00 ks_giris.pdf, Turkish, 2009.

15. Loghavi M. and Hosseinpoor A. Investigating the effect of attaching roller to moldboard plow on primary and secondary tillage operation, Proceeding of Second National Congress on Farm Machinery and Mechanization, Karaj, Iran, 2002.
16. Magdziak M The calculation of the nominal data of a turbine blade with the use of CAD software, MATEC Web of Conferences, 28, 2015, 1-4.

17. Marques Silva Soares J.M.C.N. Description standards of primary tillage implements, Soil \& Tillage Research, 57, 2000, 173-176.

18. Nor M.A.M., Rashida H., Mahyuddin W.M.F.W., Azlan M.A.M. and Mahmud J. Stress analysis of a low loader chassis, Procedia Engineering, 41, 2012, 995-1001.

19. Ozturk I. and Bastaban S.A. Research on effect of tillage implement and machines on soil aggregation, porosity and surface smoothness in seedbed preparation. International Conference on Mechanization and Energy in Agriculture, Kusadasi, Turkey, 1993.

20. Rahman R.A., Tamin M.N. and Kurdi O. Stress analysis of heavy duty truck chassis as a preliminary data for its fatigue life prediction using FEM, Jurnal Mekanikal, 26, 2008, 76-85.

21. Pietola L.M. Root growth dynamics of spring cereals with discontinuation of mouldboard ploughing. Soil Tillage Res. J., 80, 2005, 103-114.

22. Serrano J.M., Peça J.O., Silva J.M., Pinheiro A. and Carvalho M., Tractor energy requirements in disc harrow systems, Biosystems Engineering, 98, 2007, 286-296.

23. Serrano J.M.P.J.O., Pinheiro A., Carvalho M., Nunes M., Ribeiro L. and Santos F. The Effect ofGang Angle of Of fset Disc Harrows on Soil Tilth, Work Rate and Fuel Consumption Biosystems Engineering 84 (2), 2003, 171-176.

24. http://www.skf.com/group/knowledge-centre/engineering-tools/skfbearingcalculator.html.

25. Tiwari S.K. and Joshi U.K. Stress analysis of mating involute spur gear teeth, International Journal of Engineering Research \& Technology (IJERT), 1(9), 2012, 1-12.

26. Vasovic I. and Ristić M., Radosavljevic M., Milutinovic Z. and Kocic M. Stress analyses and optimization of bus chassis using software package CATIA and comparative methods, Welding and Material Testing, 4, 2013, 19-22.

27. Zahariea D. Structural analysis of a claw coupling, International Journal of Modern Manufacturing Technologies, .3(2), 2011, 117-122. 